\title{
Study on maternal and foetal outcome of pregnancy with positive glucose tolerance test by diabetes in pregnancy study group diagnostic criteria
}

\section{G. Anantha Lakshmi Satyavathi, Chitti Sudha A.*}

Department of Obstetrics and Gynaecology, GSL Medical College and General Hospital, Rajahmundry, Andhra Pradesh, India

Received: 16 July 2019

Accepted: 22 July 2019

\author{
*Correspondence: \\ Dr. Chitti Sudha A., \\ E-mail: drysudha@gmail.com
}

Copyright: (C) the author(s), publisher and licensee Medip Academy. This is an open-access article distributed under the terms of the Creative Commons Attribution Non-Commercial License, which permits unrestricted non-commercial use, distribution, and reproduction in any medium, provided the original work is properly cited.

\begin{abstract}
Background: Diabetes in Pregnancy Study group, India (DIPSI) diagnostic criteria is a single step method of screening and diagnosis of gestational Diabetes. Therefore, this prospective study was undertaken to ascertain the validity of DIPSI criteria to diagnose GDM based on pregnancy outcome in Indian population.

Method: The present Hospital based prospective study was conducted at OBGY department, GSL Medical College and General Hospital, Rajahmundry during 2013 to 2015. Women who were attending OBGY OPD for Antenatal check-ups within 24-28 weeks of GA during the study period were included in the study. Each mother at 24-28 weeks of gestation irrespective of last meal timing, fasting / non fasting was given 75 gm glucose dissolved in a glass of 200 $\mathrm{ml}$ water to drink and after two hours venous blood was collected.

Result: Out of 500 cases, 26 cases are diagnosed as having gestational diabetes by DIPSI criteria and 474 cases are Normal glucose tolerant. Maximum number 53.9\% of cases diagnosed as GDM by DIPSI are of age $>25 \mathrm{yrs}(53.9 \%)$, primigravida $(65.7 \%), \mathrm{BMI}>25(57.7 \%)$. In present study, family h/o diabetes is a risk factor for GDM

Conclusion: Our results suggest that a policy of universal screening for GDM should be adopted in all antenatal clinics and $75 \mathrm{gm}$ OGTT has a high predictive value. This single step procedure is a simple economic and feasible method. It serves both for the purpose of screening and diagnosis at the same time.
\end{abstract}

Keywords: Diabetes in pregnancy study group, Gestational diabetes mellitus, India, Pregnant women, Risk factors

\section{INTRODUCTION}

Diabetes Mellitus is a common medical complicating pregnancy. It is estimated that 5 in 200 pregnant women will develop gestational diabetes. ${ }^{1}$ Importance of GDM is that two generations (mother and child) are at risk of developing diabetes in future; predominantly type 2 diabetes mellitus. ${ }^{2}$ GDM is associated with increased incidence of maternal hypertension, pre-eclampsia, obstetric intervention and risk of developing diabetes mellitus (DM) in later life. ${ }^{3}$ Infants of diabetic mothers stand the risk of macrosomia, growth restriction, congenital malformations, respiratory distress, polycythemia, hypoglycemia, hypocalcaemia and hypomagnesaemia. ${ }^{4}$

In the Indian context, universal screening is essential as the Indian women have eleven fold increased risk of developing glucose intolerance during pregnancy compared to other ethnic groups. ${ }^{5}$ The recent data shows $16.55 \%$ prevalence of Gestational Diabetes in our country. ${ }^{6,7}$ The benefit of treatment implies the need for 
universal screening and diagnosis of gestational Diabetes mellitus.

Numerous methodologies for the diagnosis of GDM have been proposed. Diabetes in Pregnancy Study group, India (DIPSI) diagnostic criteria is a single step method of screening and diagnosis of gestational Diabetes that is $75 \mathrm{~g}$ oral glucose challenge test with 2 hour post plasma glucose $>140 \mathrm{mg} / \mathrm{d} 1$ is diagnostic of gestational Diabetes mellitus. It is modified version of WHO OGTT, in that the WHO procedure requires women to be in the fasting state, whereas DIPSI procedure is performed in the fasting/non-fasting state irrespective of the lastmealtiming. 8 Hence, this prospective study was undertaken to ascertain the validity of DIPSI criteria to diagnose GDM based on pregnancy outcome in Indian population.

Objectives of this study to assess the maternal and foetal outcome of pregnancy with positive Glucose Tolerance Test by DIPSI diagnostic criteria.

\section{METHODS}

The present Hospital based prospective study was conducted at OBGY department, GSL Medical College and General Hospital, Rajahmundry during 2013 to 2015. Women who were attending OBGY OPD for Antenatal checkups within 24-28weeks of GA during the study period were included in the study.

\section{Inclusion criteria}

All Pregnant women with Gestational age between 24 to 28 weeks attending OPD .

\section{Exclusion criteria}

- Patients with overt diabetes mellitus

- Patients with h/o Pancreatitis

\section{Data collection procedure}

Each mother at 24-28 weeks of gestation irrespective of last meal timing, fasting / non fasting was given 75 gm glucose dissolved in a glass of $200 \mathrm{ml}$ water to drink and after two hours venous blood was collected .This was analysed in auto analyser in our central laboratory using GOD-POD method.

The DIPSI criteria for diagnosis of gestational diabetes using two hour plasma glucose value of $140 \mathrm{mg} / \mathrm{dl}$ or more was used as the cut off value to diagnose GDM. Those mothers having blood glucose values more than $140 \mathrm{mg} / \mathrm{dl}$ were marked as having GDM and the rest with blood glucose values less than $140 \mathrm{mg} / \mathrm{dl}$ were marked as normal glucose tolerant.

The mothers having GDM were offered treatment. GDM patients with $2 \mathrm{hr}$ blood glucose more than 140mg/dl were given dietary advice in the form of medical nutrition therapy (MNT) initially for two weeks.

The cases in which MNT fails to achieve control i.e. to maintain, FPG $=90 \mathrm{mg} / \mathrm{dl}$ and $/$ or $11 \frac{1}{2} \mathrm{hr} P P G=120 \mathrm{mg} / \mathrm{dl}$ ,insulin was initiated All screen positive mothers were followed up and encouraged to deliver in our hospital., pregnancy complications like hypertension, polyhydramnios, intrauterine foetal death, mode of delivery, birth weight, Apgar score, still birth, or preterm labour and congenital abnormality in the babies were recorded.

\section{Statistical analysis}

Descriptive statistics such as mean, SD and percentage was used to present the data. Association between variables was done by using Chi-square test. A p-value less than 0.05 were considered as significant. Data analysis was performed by using software SPSS v16.

\section{RESULTS}

Out of 500 cases 26 cases are diagnosed as having gestational diabetes by DIPSI criteria and 474 cases are Normal glucose tolerant.

Table 1: Relation between GDM with Age and BMI.

\begin{tabular}{|c|c|c|c|}
\hline Characteristics & GDM & Non GDM & $\begin{array}{l}\mathbf{P} \\
\text { value }\end{array}$ \\
\hline \multicolumn{4}{|l|}{ AGE } \\
\hline$\leq 20$ & $3(11.5 \%)$ & $159(33.5 \%)$ & \multirow{4}{*}{0.000} \\
\hline $21-25$ & $9(34.6 \%)$ & $222(46.9 \%)$ & \\
\hline $26-30$ & $12(46.2 \%)$ & $83(17.5 \%)$ & \\
\hline$>30$ & $2(7.7 \%)$ & $10(2.1 \%)$ & \\
\hline \multicolumn{4}{|l|}{ BMI } \\
\hline$<20$ & $1(3.9 \%)$ & $48(10.1 \%)$ & \multirow{4}{*}{0.002} \\
\hline $20.1-25$ & $10(38.4 \%)$ & $287(60.6 \%)$ & \\
\hline $25.01-30$ & $12(46.2 \%)$ & $135(28.4 \%)$ & \\
\hline $30.01-35$ & $3(11.5 \%)$ & $4(0.9 \%)$ & \\
\hline \multicolumn{4}{|l|}{ GRAVIDA } \\
\hline Primi & $17(65.4 \%)$ & $235(49.6 \%)$ & \multirow{2}{*}{0.117} \\
\hline Multi & $9(34.6 \%)$ & $239(50.4 \%)$ & \\
\hline
\end{tabular}

In the present study out of 26 cases of GDM $11.5 \%$, $34.6 \%, 46.2 \%, 7.7 \%$ cases are of age group <20, 21-25, $26-30,>30$ respectively.

Out of 474 cases of NGT $33.5 \%, 46.8 \%, 17.5 \%, 2.2 \%$ are of age group $<20,21-25,26-30,>30$ respectively. Totally $53.9 \%$ of cases are of age $>25$ in GDM group, $19.7 \%$ of cases are of age $<25$ which is statistically significant ( $p$ value 0.00 ) showing age $>25$ is a risk factor for GDM.

The above table represents out of 26 cases of GDM 3.9\%, $38.4 \%, 46.2 \%, 11.5 \%$ of cases are of BMI <20, 20.01-25, 25.01-30, 30.01-35 respectively. 
In 474 cases of NGT $10.1 \%, 60.6 \%, 28.4 \% 0.9 \%$ of cases are of BMI ranging from <20, 20.01-25, 25.01-30, 30.0135 respectively.

Over all $57.7 \%$ of cases are of BMI>25 in GDM group, $29.3 \%$ of cases are of $\mathrm{BMI}<25$ which is statistically significant $(\mathrm{P}=0.002)$ which indicates that $\mathrm{BMI}>25$ is strongly associated with occurrence of GDM.
The above table represents that out of 26 cases of GDM $65.4 \%$ of cases are primi gravida, $34.6 \%$ of cases are multi gravida. out of 474 cases of NGT $49.6 \%$ cases are primi garvida, $50.4 \%$ of cases are multi gravida which is statistically insignificant $(\mathrm{p}=0.117)$ which indicates that the incidence of GDM is not related with parity.

Table 2: Association of other risk factors.

\begin{tabular}{|lllll|}
\hline Other risk factors & No of cases & GDM & Non GDM & p value \\
\hline H/o still birth or IUD & $41(8.2 \%)$ & $6(23.1 \%)$ & $35(7.3 \%)$ & 0.005 \\
\hline H/o congenital anamolies & $3(0.7 \%)$ & $3(11.5 \%)$ & $0(0 \%)$ & 0.0001 \\
\hline Family H/o DM & $53(10.6 \%)$ & $12(46.1 \%)$ & $41(8.6 \%)$ & 0.0001 \\
\hline
\end{tabular}

The above table represents association of GDM with risk factors. Out of 500 cases of present study group 41 $(8.2 \%)$ cases had h/o stillbirth of which $6(23.1 \%)$ cases are diagnosed as GDM and $35(7.3 \%)$ cases are NGT, which is statistically significant $(\mathrm{p}=0.005)$ showing that $\mathrm{h} / \mathrm{o}$ still birth is strongly associated with occurrence of GDM.

Table 3: Maternal Complications in GDM.

\begin{tabular}{|llll|}
\hline $\begin{array}{l}\text { Maternal } \\
\text { complications }\end{array}$ & Total No & GDM & NGT \\
\hline UTI & $25(5 \%)$ & $4(15.3 \%)$ & $21(4.4 \%)$ \\
\hline IUGR & $3(0.6 \%)$ & $0(0 \%)$ & $3(0.63 \%)$ \\
\hline Preeclampsia & $16(3.2 \%)$ & $6(23.1 \%)$ & $10(2.1 \%)$ \\
\hline Polyhydromnios & $15(3 \%)$ & $4(15.3 \%)$ & $11(2.3 \%)$ \\
\hline
\end{tabular}

Out of 500 cases $3(11.5 \%)$ cases had H/O congenital anomalies, all 3 cases were found to be GDM by DIPSI diagnostic criteria which is statistically significant $(\mathrm{P}<0.0001)$ when compared with NGT cases showing that $\mathrm{h} / \mathrm{o}$ congenital anomalies is a risk factor for GDM.

Table 4: Pregnancy Outcome in GDM Cases.

\begin{tabular}{|ll|l|}
\hline Outcome & No. of cases & $\%$ \\
\hline Vaginal Delivery & 15 & $57.7 \%$ \\
\hline Cesarean Sections & 10 & $38.4 \%$ \\
\hline Preterm Labour & 3 & $11.5 \%$ \\
\hline Requirement of Insulin & 2 & $7.6 \%$ \\
\hline Instrumental Delivery & 1 & $3.84 \%$ \\
\hline IUD & 1 & $3.84 \%$ \\
\hline
\end{tabular}

Out of 500 cases, $53(10.3 \%)$ cases had family h/o diabetes mellitus of which $12(46.1 \%)$ cases are diagnosed as GDM by DIPSI $41(8.6 \%)$ cases are NGT which is statistically significant $(\mathrm{P}<0.0001)$. So, family $\mathrm{h} / \mathrm{o}$ diabetes mellitus is a risk factor for GDM. Out of 26 cases of GDM 4 (15.3\%) cases had UTI,6 (23.1\%) cases had pre-eclampsia, $4(15.3 \%)$ cases had polyhydromnios as a complication during their antenatal period.
In 474 cases of NGT, 21 (4.4\%) cases had UTI, 3(0.63\%) cases had IUGR, $10(2.1 \%)$ cases had preeclampsia, 11 $(2.3 \%)$ cases had polyhydromnios.

The above table represents out of 26 cases of GDM $57.7 \%$ of cases underwent NVD, 38.4\% of cases are delivered by caesarean section, $11.5 \%$ of cases underwent spontaneous preterm labour, $7.6 \%$ of cases required insulin for their treatment, $3.84 \%$ of cases required instrumental delivery, $3.84 \%$ of cases had IUD.

Table 5: Foetal outcome in GDM Cases.

\begin{tabular}{|lll|}
\hline Foetal Outcome & No of cases & $\%$ \\
\hline Hyperblirubinemia & 4 & $15.3 \%$ \\
\hline Hypoglycemia & 3 & $11.5 \%$ \\
\hline Respiratory disterss & 2 & $7.6 \%$ \\
\hline Macrosomia & 1 & $3.84 \%$ \\
\hline Hypocalcemia & 0 & $0 \%$ \\
\hline
\end{tabular}

The above table represents out of 26 cases of GDM 7 cases admitted in NICU 4(15.3\%) cases got admitted in v/o hyperbilirubinemia, 3(11.5\%) cases in v/o RDS.2 $(7.6 \%)$ cases in v/o RDS, $1(3.84 \%)$ case in v/o macrosomia and low APGAR score.

\section{DISCUSSION}

\section{Universal versus selective screening}

In order to reduce the burden of screening on women and the health care system, the concept of selective screening was introduced. Selective screening originally consisted of taking a personal and family history in order to identify a high-risk population in need of further directed testing. ${ }^{9,10}$

Women with any of the risk factors were advised to perform a $50 \mathrm{~g}$ glucose challenge test. Screening by risk factors alone has a sensitivity of $63 \%$ and a specificity of $56 \% 10$. In other words, $37-50 \%$ of women with GDM 
may go undiagnosed using this approach. To this low sensitivity, most guidelines prior to 1995 recommended universal biochemical screening. Recent data and reviews of existing data suggesting that women at low risk for GDM could be exempt from biochemical screening led the ADA to revise their guidelines to recommend that women who are 25 years old or younger, who are Caucasian and are not obese $(<20 \%$ over desired body weight or BMI $\leq 27 \mathrm{~kg} / \mathrm{m} 2$ ) could be exempt from screening. ${ }^{10-12}$ This revised concept of selective screening will still result in screening $90 \%$ of all pregnant patients. ${ }^{13}$ Thus many clinicians continue the practice of universal screening.

In present study $88.4 \%$ (23) of GDM cases are having one or more risk factors for the development of GDM, $11.5 \%$ (3) of cases are without any risk factors which would have been missed if selective screening was done. This implies that universal screening is mandatory to identify GDM cases, prevent maternal foetal mortality and morbidity.

\section{Incidence of $G D M$}

The prevalence of GDM varies from 5-15\% depending on the population studied. According to study conducted by Balaji et al. the prevalence of GDM is $13.4 \%$, In present study the out of 500 cases 26 (5.2) \% cases are diagnosed as GDM by DIPSI diagnostic criteria. 474 (94.8\%) are Normal Glucose Tolerant [NGT]. The prevalence of GDM in present study is $5.2 \%$ which is comparable to the study conducted by Wahi et al, and prevalence was $6.94 \%$, similar study conducted by $\mathrm{V}$ Seshiah et al. showed prevalence of $16.2 \%$. $^{8,14,15}$

\section{Relation between GDM and AGE}

Various studies have shown that maternal age is highly correlated with risk of GDM. According to Battacharya et al, the incidence of GDM in relation to age $>25$ is $39.75 \% .^{16}$

In the present study, statistically significant showing strong relation between GDM and increased age was found. In present study 53.9\% of GDM are >25years which can be comparable to the study conducted by DIXON DRD et.al and found to be $51.2 \% .^{17}$

\section{Relation between GDM and parity}

Higher parity has been found to be associated with higher prevalence of GDM in a few studies. ${ }^{18,19}$ Granat et al. and his colleagues did not find any correlation between parity and alterations of carbohydrate metabolism in their study. ${ }^{20}$

In present study, no relation between GDM and parity which is comparable to study done by Granat et al.. ${ }^{20}$
Though insignificant the incidence of GDM was found to be more in case of primigravida . Jang et al. found greater ratio of women with GDM in the group with parity $>2$, in comparison to primiparas but after controlling for age, pre-pregnancy BMI, height, family history of diabetes mellitus and weight gain during pregnancy, the results were not statistically significant. ${ }^{21}$

Though above studies has shown more association of GDM with multi gravid in present study out of 17 $(65.4 \%), 11(64.7 \%)$ cases fall underage group $>25,10$ $(58.8 \%)$ cases are of BMI $>25$ which is an independent risk factor for GDM. $9(52.9 \%)$ of cases had family history of DM which is also a risk factor for GDM could be the reason for GDM to be more prevalent in primigravid. Martin and Nagy also reported $54.8 \%$ and $52 \%$ cases of GDM with positive history of diabetes in first-degree relatives respectively in their series. ${ }^{22,23}$

\section{Relation between GDM and BMI}

Obesity is an independent risk factor for GDM, causing hormonal imbalance of carbohydrate regulation mechanism and insulin sensitivity. Gestational diabetes and obesity have adverse outcomes in pregnancy like caesarean delivery, perinatal deaths, preeclampsia, birth defects, macrosomia associated with subsequent childhood obesity. ${ }^{24}$

In present study, obesity is strongly associated with occurrence of GDM. A study done by Hadaegh F et al, showed that BMI $>25 \mathrm{~kg} / \mathrm{m} 2$ more prevalent in GDM subjects. ${ }^{24}$ Out of $57.7 \%$ (15) of cases $56.2 \%$ (9) of cases underwent lscs, $25 \%$ of cases had preeclampsia during their antenatal period, $1(3.84 \%)$ of cases delivered a macrosomic baby which shows obesity is an independent risk factor for GDM.

\section{Relation between GDM and family $\mathrm{H} / O$}

Family history of diabetes mellitus has been reported to be associated with higher chances of developing GDM. ${ }^{19,25-27}$ In present study, a significantly higher per cent of women with GDM had positive family history of diabetes mellitus. Seshiah et al. observed a significant association between the family history of diabetes mellitus and the occurrence of GDM among pregnant women. ${ }^{25}$

In present study, family h/o diabetes is a risk factor for GDM as observed by Seshiah et al. ${ }^{25}$

\section{Relation between GDM and H/O still birth}

Poor past obstetric history of stillbirth and neonatal deaths are important factors in detection of GDM. Turki Gaisim showed that 14\% GDM had history of unexplained stillbirth. In present study out of 26 cases of GDM $23.1 \%$ of cases had h/o stillbirth/Neonatal death. ${ }^{28}$ 


\section{Relation between GDM and preeclampsia}

Multiple studies have investigated the risk of gestational hypertension and pre-eclampsia to occur in women with GDM. Casey et al. compared 61,209 non-diabetic pregnant women to 874 women with diet treated GDM. ${ }^{29}$ They documented a higher risk for hypertensive disorders reaching $17 \%$ in the GDM population vs $12 \%$ in nondiabetic women. Joffe et al. in the Calcium for Preeclampsia Prevention (CPEP) trial followed 4589 nulliparous women. They demonstrated that among women with GDM and increased risk for pre-eclampsia specifically as well as for all hypertensive disorders. ${ }^{30}$ Similar results were reported by Yogev et al, who studied 1813 patients with GDM and demonstrated that preeclampsia in GDM subjects is diagnosed at a younger age, usually during the first pregnancy, in more obese women and in those with a higher gestational weight gain. ${ }^{31}$

In the present study, the incidence of preeclampsia in association with GDM cases is found to be $23.1 \%$. Out of 6 cases of preeclampsia,4(66.6\%) of cases are primi gravid, age $>25$. A prospective study on 1310 women in Iran showed that GDM women had higher rate of hypertension, polyhydramnios and caesarean section. ${ }^{32}$

\section{GDM and its management}

In present study, Authors found dietary intervention along with glucose monitoring as the primary therapeutic choice in all the studies meeting our inclusion criteria and insulin therapy was initiated if dietary modification failed to control glycemic levels. Based on the data from present study, results of our analysis indicated that treating GDM women with a specific therapeutic intervention decreases incidence of many adverse pregnancy outcomes. Authors observed significant decrease in the risk of macrosomia, LGA births and shoulder dystocia in infants. Reduction in the risk of macrosomic and LGA babies is likely to have important implications for the infants in the long term also as these outcomes have been linked with delayed motor development, obesity and diabetes later in life.

In the present study out of 26 cases $92.4 \%$ cases were managed with MNT, whereas $7.6 \%$ of cases required insulin for achieving glycemia.

For the patients who required insulin, the blood glucose level even after 2 weeks of MNT was $>140 \mathrm{mg} / \mathrm{dl}$. So, advised insulin Human acrtrapidat a dose of $6 \mathrm{u}$ thrice daily, follow up was done by Glucose monitoring, USG abdomen, NST and induced at 38 weeks, one case required outlet foreceps for delivery, one underwent emergency lscs in v/o foetal distress.

Out of 26 cases of GDM one (3.84\%) had IUD, this case was diagnosed as GDM at 26 weeks of gestation .Her OGTT after $2 \mathrm{hr}$ of glucose intake was $186 \mathrm{mg} / \mathrm{dl}$. Patient was advised MNT, daily glucose monitoring. Inspite of the above treatment patient reported loss of foetal movements and diagnosed IUD, weight of the baby $1900 \mathrm{gms}$ and it is more than the expected weight of the foetus at 27 weeks.

\section{GDM and polyhydromnios}

The association between diabetes and polyhydramnios is well known. ${ }^{33}$ A commonly supported theory is that increased amniotic fluid volume in diabetic pregnancies could be a result of maternal hyperglycemia which, in turn, produces fetal hyperglycemia and osmotic diuresis. It has consistently been reported that approximately 15\% of pregnancies complicated by polyhydramnios occur in diabetic women. ${ }^{34}$ This figure was consistent with our study. Authors found that 4 of our polyhydramnios patients $(15.3 \%)$ were diabetic. Out of $4(15.3 \%)$ of cases one case had congenital anomalies, and one case delivered a macrosomia baby.

\section{GDM and preterm birth}

The link between GDM and spontaneous preterm birth is still controversial. Hedderson et al, showed in a large cohort study that GDM was an independent risk factor for spontaneous preterm birth $(\mathrm{RR}=1.42$, 95\% CI: 1.151.77)..$^{35}$ On the other hand, Yogev et al, found that the rate of spontaneous preterm delivery was not increased in GDM compared to non-GDM patients. ${ }^{36}$ Nevertheless, both studies found a relationship between higher glucose values in the oral glucose tolerance test (OGTT) or higher mean blood glucose levels and preterm birth.

In present study out of 7 cases of preterm labour $4(0.84 \%)$ of cases are NGT, $3(11.5 \%)$ of cases are GDM cases which shows rate of spontaneous preterm delivery is more in GDM compared to NGT as said above.

\section{Mode of delivery}

The results of the study demonstrate that untreated women with borderline GDM had an increased rate of caesarean delivery compared to controls $(29.6 \%$ vs. $20.2 \%, \mathrm{P}=0.02$ ), as did had women with treated GDM compared to controls (adjusted OR=2.1; 95\% CI 1.3-3.6). Women with treated GDM, even though birth weight was normalized, remained at a higher risk for caesarean delivery of approximately 33\%. This suggests that diagnosis of GDM leads to a lower threshold for intervention by caesarean delivery, independent of birth weight. Similar rates of caesarean deliveries were reported by Casey et al. who concluded that women with GDM had a $30 \%$ rate of caesarean delivery, compared to $17 \%$ in the general population. ${ }^{29}$

In present study, out of 474 cases of NGT, the rate of caesarean section, vaginal delivery, instrumental delivery is $19.8 \%, 70.05 \%$, and $2.1 \%$ respectively. Out of 26 cases of GDM the rate of caesarean section, vaginal delivery, 
instrumental delivery is $10(38.6 \%), 15(65.1 \%)$ and $1(3.84$ $\%)$ respectively. The main indications for CS being post caesarean, cephalopelvic disproportion, fetal distress, malpresentation and macrosomic babies. The rate of caesarean section in our study $(38.6 \%)$ is comparable to the study by Casey et al. ${ }^{29}$

A similar study from Saudi Arabia was done and reported that, $74.6 \%$ spontaneous vertex deliveries, and $21.6 \%$ lower segment caesarean section in 685 women with gestational diabetes mellitus. ${ }^{37}$

The risk is increased not solely for caesarean deliveries, but similarly and independently increased for operative deliveries. Compared with non-diabetics, women with GDM are prone to higher risk of vaginal operative deliveries. The degree of glucose intolerance (determined by FPG $>105 \mathrm{mg} / \mathrm{dl}$ ) and maternal weight are independent variables that significantly increase the risk for operative delivery. ${ }^{38}$

The mode of delivery was also influenced by polyhydramnios. The overall incidence of polyhydramnios in our study group is $3 \%$. The frequency of normal vaginal delivery in patients with polyhydramnios in our study was $53.3 \%$. The rate was reported as $68.2 \%$ by Mathew $\mathrm{M}$ and $79.5 \%$ by Chen $\mathrm{KC}$ respectively which can be comparable to present study. $4(26.6 \%)$ cases of polyhydramnios are delivered by instrumental delivery, 3(20\%) of cases are delivered by caesarean section. ${ }^{39,40}$

\section{Macrosomia and GDM}

A Study conducted by Ehrenberg et al. in 2004 in Ohio, US, that found that the prevalence of macrosomia was $11.8 \%$ of population sample. ${ }^{41}$ In the present study, the incidence of macrosomia is $7 \%$ which is comparable to a study conducted by Hajy-Ebrahim-Tehrani et al. in Iran the rate was determined as $5.8 \%$ in the study. ${ }^{42}$

Fetal macrosomia is a common adverse infant outcome related to GDM, especially if GDM is unrecognized and untreated. For the infant, macrosomia increases the risks of shoulder dystocia, clavical fractures, and brachialplexus injury and is also associated with depressed 5-min Apgar scores and increased rates of admission to neonatal intensive care unit. ${ }^{43}$

In present study macrosomia i.e. babies with birth weight $\geq 4000 \mathrm{~kg}$ (90th percentile) was observed in $3.84 \%$ of newborns of GDM cases which is 4200 gms, delivered by caesarean section. Her blood glucose level after 2 hours of taking $75 \mathrm{gms}$ OGTT was $198 \mathrm{mg} / \mathrm{d}$ at 24 weeks POG. The apgar scores being $7 / 10$ at $5 \mathrm{~min}, 10 / 10$ at $10 \mathrm{~min}$. The rate of macrosomia in NGT cases is $3.16 \%$ of newborn cases which is showing the incidence of macrosomia is almost equal in both the groups. It is comparable to a similar study done by Balaji V. et al. in 2011, showed the equal incidence of macrosomia in treated GDM women and normal glucose tolerant (NGT) women and concluded that intervention helped in maintaining the pregnancy outcome in GDM women equivalent to that of NGT women. ${ }^{8}$ A study conducted by Vedavathi KJ et al. in 2010 on Influence of Gestational Diabetes Mellitus on Fetal growth parameters concluded that despite the attempts for good glycemic control there is a risk of macrosomia in GDM. ${ }^{44}$

\section{CONCLUSION}

The rise in prevalence of Gestational Diabetes in our community and its associated increased risk of pregnancy and delivery complications justifies a need to screen pregnant mothers who attend the antenatal clinic. Our results suggest that a policy of universal screening for GDM should be adopted in all antenatal clinics and 75 gm OGTT has a high predictive value. This single step procedure is a simple economic and feasible method. It serves both for the purpose of screening and diagnosis at the same time. This cost-effective and evidence-based procedure meets our responsibility of offering a singlestep definitive glucose test to every pregnant woman belonging to any socio-economic status. So, looking towards the socio-demographic characteristics of our patients it can be followed in our region to achieve a better outcome.

Funding: No funding sources

Conflict of interest: None declared

Ethical approval: The study was approved by the Institutional Ethics Committee

\section{REFERENCES}

1. Albert RE. Diabetes in pregnancy. Obstetrics and Gynecology. Clinics of North America. W.B. Saunders company. 1996,23(1): 10 .

2. Dornhost A, Rossi M. Risk and prevention of Type 2 Diabetes in women with gestational diabetes. Diabetes Care. 1998;21(2):B43-9.

3. Davey RX, Hamblin PS. Selective versus universal screening for gestational diabetes mellitus: An evaluation of predictive risk factors. Med J Aust. 2001 Feb;174(3):118-21.

4. Opara PI, Jaja T, Onubogu UC. Morbidity and mortality amongst infants of diabetic mothers admitted into a special care baby unit in Port Harcourt, Nigeria. Ital J Pediatr. 2010 Dec;36(1):77.

5. Dornhorst A, Paterson CM, Nicholls JS, Wadsworth J, Chiu DC, Elkeles RS, et al. High prevalence of gestational diabetes in women from ethnic minority groups. Diabetic Medicine. 1992 Nov;9(9):820-5.

6. Hunt K, Schuller K. The increasing prevalence of Diabetes in pregnancy obstet gynecol clin North Am. 2007:34(2):173-7.

7. Seshaiah V, Balaji V, Balaji MS, Sanjeevi CB, Green A. Gestational Dabetes in India. J Assoc Physicians India. 2004 Sep;52:707-11. 
8. Balaji V, Balaji M, Anjalakshi C, Cynthia A, Arthi T, Seshiah V. Diagnosis of gestational diabetes mellitus in Asian-Indian women. Indi $\mathbf{J}$ endocrinol Metaboli. 2011 Jul;15(3):187-90.

9. Routine screening for gestational diabetes mellitus in pregnancy. SOGC Committee Opinion no.1. J Obstet Gynaecol Can; 1992.

10. O'Sullivan JB, Mahan CM, Charles D, Dandrow RV. Screening criteria for high-risk gestational diabetic patients. Am J Obstetr Gynecol. 1973 Aug 1;116(7):895-900.

11. Coustan DR, Nelson C, Carpenter MW, Carr SR, Rotondo L, Widness JA. Maternal age and screening for gestational diabetes: a population-based study. Obstet Gynecol. 1989;73(4):557-61.

12. Naylor CD, Sermer M, Chen E, Farine D. Selective screening for gestational diabetes mellitus. Toronto Trihospital Gestational Diabetes Project Investigators. N Engl J Med. 1997;337(22):1591-6.

13. Danilenko-Dixon DR, Van Winter JT, Nelson RL, Ogburn Jr PL. Universal versus selective gestational diabetes screening: application of 1997 American Diabetes Association recommendations. Am J Obstetr Gynecol. 1999 Oct 1;181(4):798-802.

14. Wahi P, Dogra V, Jandial K, Bhagat R, Gupta R, Gupta S, et al. Prevalence of gestational diabetes mellitus (GDM) and its outcomes in Jammu region. J Assoc Physicians India. 2011 Apr;59(4):227-30.

15. Seshiah V, Das AK, Balaji V, Joshi SR, Parikh MN, Gupta S. Gestational diabetes mellitus-guidelines. JAPI. 2006 Aug;54:622-8.

16. Bhattacharya C, Awasthi RT, Kumar S, Lamba PS. Routine screening for gestational diabetes mellitus with glucose challenge test in antenatal patients. J Obstet Gynaecol India. 2001;51:75-8.

17. Danilenko-Dixon DR, Van Winter JT, Nelson RL, Ogburn Jr PL. Universal versus selective gestational diabetes screening: application of 1997 American Diabetes Association recommendations. Am J Obstetr Gynecol. 1999 Oct 1;181(4):798-802.

18. Gestational diabetes mellitus in India. J Assoc Physicians India 2004 sep;52:707-11.

19. Zargar AH, Sheikh MI, Bashir MI, Masoodi SR, Laway BA, Wani AI, et al. Prevalence of gestational diabetes mellitus in Kashmiri women from the Indian Subcontinent. Diabetes Res Clin Pract. 2004 Nov $1 ; 66(2): 139-45$.

20. Granat M, Sharf M, Copper A. Glucose intolerance during pregnancy. Obstet Gynecol, 1979,53:157-61.

21. Jang HC, Min HK, Lee HK, Cho NH, Metzger BE. Short 24. stature in Korean women: a contribution to the multifactorial predisposition to gestational diabetes mellitus. Diabetologia. 1998 Jun 1;41(7):778-83.

22. Martin RW: Diabetes mellitus associated with pregnancy. Manual of clinical problems in obstetrics and Gynecology. Ed. Rivlin ME, Martin RW, Little Brown and Company, 4th Edition, Boston, New York, Toronto, London. 1994,73-74.
23. Nagy G. Postprandial blood glucose screening for gestational diabetes. Zentralb Gynakol, 1993;115(1):36-40.

24. Hadaegh F, Tohidi M, Harati H, Kharandish M, Rahimi S. Prevalence of gestational diabetes mellitus in Southern Iran. Endocr Pract. 2005 Aug 26;11(5):313-8.

25. Seshiah V, Balaji V, Balaji MS, Paneerselvam A, Arthi T, Thamizharasi M, et al. Prevalence of gestational diabetes mellitus in South India (Tamil Nadu)- a community based study. J Assoc Physicians India. 2008 May;56:329-33.

26. Swami SR, Mehetre R, Shivane V, Bandgar TR, Menon PS, Shah NS. Prevalence of carbohydrate intolerance of varying degrees in pregnant females in western India (Maharashtra) - A hospital-based study. J Indian Med Assoc. 2008;106(11):712-4.

27. Kim C, Liu T, Valdez R, Beckles GL. Does frank diabetes in first degree relatives of a pregnant woman affect the likelihood of her developing gestational diabetes mellitus or nongestational diabetes? Am J Obstet Gynecol. 2009 Dec 1;201(6):576-e1.

28. Gasim T. Gestational Diabetes Mellitus: Maternal and Perinatal outcome in 220 Saudi women. A prospective Study. Oman Med J. 2012 Mar;27(2):140-4.

29. Casey BM, Lucas MJ, Mcintire DD, Leveno KJ. Pregnancy outcomes in women with gestational diabetes compared with the general obstetric population. Obstet Gynecol. 1997;90(6):869-73.

30. Joffe GM, Esterlitz JR, Levine RJ, Clemens JD, Ewell MG, Sibai BM, et al. The relationship between abnormal glucose tolerance and hypertensive disorders of pregnancy in healthy nulliparous women. Calcium for Preeclampsia Prevention (CPEP) Study Group. Am J Obstet Gynecol. 1998;179(4):1032-7.

31. Yogev Y, Xenakis EM, Langer O. The association between preeclampsia and the severity of gestational diabetes: the impact of glycemic control. Am J Obstet Gynecol. 2004;191(5):1655-60.

32. Keshavarz M, Cheung NW, Babaee GR, Moghadam HK, Ajami ME, Shariati M. Gestational diabetes in Iran: incidence, risk factors and pregnancy outcomes. Diabetes research and clinical practice. 2005 Sep 1;69(3):279-86.

33. Vink JY, Poggi SH, Ghidini A, Spong CY. Amniotic fluid index and birth weight: Is there a relationship in diabetes with poor glycemic control? Am J Obstet Gynecol. 2006;195(3):848-50.

34. Dashe JS, Nathan L, Mclntire D, Leveno K. Correlation between amniotic fluid glucose concentration and amniotic fluid volume in pregnancy complicated by diabetes. Am J Obstet Gynecol. 2000 Apr;182(4):901-4.

35. Hedderson MM, Ferrara A, Sacks DA. Gestational diabetes mellitus and lesser degrees of pregnancy hyperglycemia: association with increased risk of spontaneous preterm birth. Obstet Gynecol. 2003 Oct 1;102(4):850-6. 
36. Yogev Y, Langer O. Spontaneous preterm delivery and gestational diabetes: the impact of glycemic control. Arch Gynecol Obstet. 2007 Oct $1 ; 276(4): 361-5$.

37. Malak M. Al-Hakeem. Pregnancy outcome of getational diabetic mother: experience in a tertiary centre. Journal of family and community medicine 2006;13(2).

38. Yogev Y, Ben-Haroush A, Chen R, Glickman H, Kaplan B, Hod M. Active induction management of labor for diabetic pregnancies at term; mode of delivery and fetal outcome--a single center experience. Eur J Obstet Gynecol Reprod Biol. 2004;114(2):166-70.

39. Mathew M, Saquib S, Rizvi SG. Polyhydramnios. Risk factors and outcome. Saudi Med J. 2008;29(2):256-60.

40. Chen KC, Liou JD, Hung TH, Kuo DM, Hsu JJ, Hsieh CC, et al. Perinatal outcomes of polyhydramnios without associated congenital fetal anomalies after the gestational age of 20 weeks. Chang Gung Med J. 2005;28(4):222-8.

41. Ehrenberg HM, Mercer BM, Catalano PM. Catalano, the influence of obesity and diabetes on the prevalence of macrosomia, Am J Obstet Gynecol. 2004 Sep;191(3):964-8.

42. Tehrani FH, Kazemi H, Kordi M. Prevalence and outcome of the macrosomic infants. Acta Medica Iranica. 2007;45(6):505-9.

43. Jolly MC, Sebire NJ, Harris JP, Regan L, Robinson S. Risk factors for macrosomia and its clinical consequences: a study of 350,311 pregnancies. Eur J Obstetr Gynecol Reproduc Biol. 2003 Nov 10;111(1):9-14.

44. Vedavathi KJ, Swamy RM, Shekharappa KR, Venkatesh G, Veerananna HB. Influence of Gestational Diabetes Mellitus on Fetal growth parameters. Int J Biol Med Res. 2011;2(3):832-4.

Cite this article as: Satyavathi G.A.L., Chitti Sudha A. Study on maternal and foetal outcome of pregnancy with positive glucose tolerance test by diabetes in pregnancy study group diagnostic criteria. Int J Reprod Contracept Obstet Gynecol 2019;8:3510-7. 